\title{
A simple method for making small lesions in the limbic system of the white rat
}

\author{
MELVIN L: GOLLDSTEIN \\ Indiana University at Kokomo, Kokomo, Indiana 46901
}

\begin{abstract}
The operating technique for producing small lesions in the limbic system of the rat is described. The method for placing the animal into the stereotaxic instrument is described, and some typical lesions of the limbic system, obtained by this method, are reproduced.
\end{abstract}

Small lesions, accurately placed, may be produced in various structures of the limbic system of the white rat by the following method. The lesions are produced electrolytically with the aid of a Baltimore rat stereotaxic instrument. The lesioning electrode can be made from a No. 23-ga. "Yale" 11/2-in. stainless steel hypodermic needle which is insulated, except at the tip, with Epoxylite.

The animal is anesthetized with $.3 \mathrm{cc}$ sodium pentobarbital and then placed into the stereotaxic instrument. Supplementary injections of $.1 \mathrm{cc}$ sodium pentobarbital may be used if necessary to prevent the rat from coming out of the anesthetic during the operation. The rat is then placed into the stereotaxic instrument. When the rat's head is properly inserted into the ear bars of the instrument, the head can be moved up and down gently with a swivel motion, and the surface of the skull is parallel with the stereotaxic instrument. After the head is made fast in the stereotaxic instrument, an incision is made along the midline of the scalp. The skin and fascia are retracted with hemostats, and small burr holes are made in the skull at the appropriate coordinates. The stainless steel electrode is inserted into the brain through the burr holes. A $2.0-\mathrm{mA}$ anodal current, lasting for $20 \mathrm{sec}$, obtained from a commercial lesion-making device, is used to produce lesions of the septal nuclei. Variations in the location and size of the septal lesions may be obtained by varying the stereotaxic coordinates and the current intensity from $.5 \mathrm{~mA}$ for $10 \mathrm{sec}$ and to $1.0 \mathrm{~mA}$ for $10 \mathrm{sec}$.

The stereotaxic coordinates used for septal lesions vary, depending upon the size of the lesion to be made, from $0 \mathrm{~mm}$ anterior to the bregma, $3.0 \mathrm{~mm}$ lateral to the midline, $5.5 \mathrm{~mm}$ below the dural tissue at an angle of

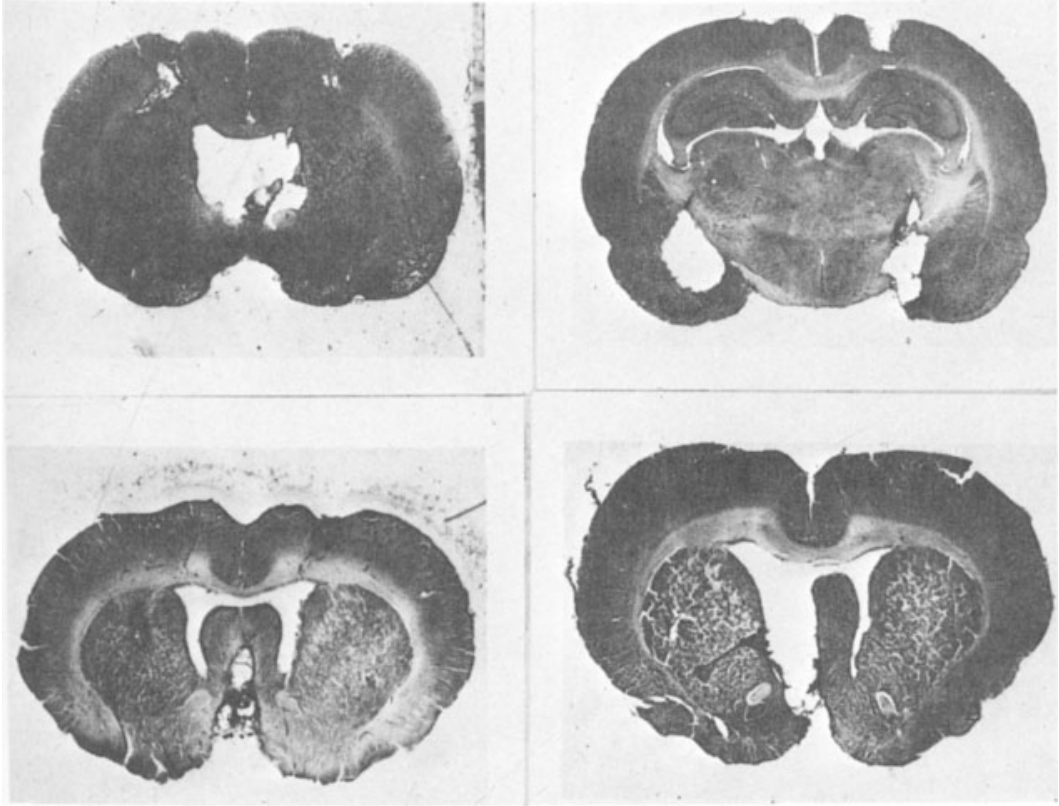

Figure 1. Typical lesions of the septal nuclei, amygdaloid complex, medial septal, and lateral septal areas. (Reading from left to right and top to bottom.)

Preparation of this report was supported by Grant 26-631-32 awarded by the Indiana University Office of Research and Advanced Studies. 
$25 \mathrm{deg}$ toward the midline, to $1.0 \mathrm{~mm}$ anterior to the bregma, $3.0 \mathrm{~mm}$ lateral to the midline, $5.5 \mathrm{~mm}$ below thedural tissue at an angle of $25 \mathrm{deg}$ toward the midline. The stereotaxic coordinates used for lesions of the amygdaloid complex are $2.5 \mathrm{~mm}$ posterior to the bregma, $4.5 \mathrm{~mm}$ lateral to the midline, $8.0 \mathrm{~mm}$ below the dural tissue.

At the completion of the operation, the wound is closed with wound clips, and the animal is permitted to recover in the home cage. Recovery is complete after 3 or 4 days, but a longer period, such as a week to 10 days is sometimes used, before behavioral testing is undertaken, in order to insure complete postoperative recovery.

Figure 1 shows some typical results of lesions of the septal nuclei and amygdaloid complex. The photographs may be compared with appropriate sections taken from the Kong and Klippel (1963) Stereotaxic Atlas in order to verify, more exactly, the location and extent of the lesions.

\section{REFERENCE}

Konig, J. R. R., \& Klippel, R. A. The rat brain: A stereotaxic atlas. Baltimore: Williams \& Wilkins, 1963.

(Received for publication April 24, 1975.) 